simply reduced to an intralinguistic model? - one does so at one's peril.

Professor Dummett's conviction that "we have now reached a situation" where what he postulates to be the fundamental philosophic problem, the theory of meaning, "can be resolved to the satisfaction of everyone" and, above all, be successfully resolved "within a finite time", is one of radical innocence. It may have at its core a certain personal element-even the most abstract, analytical thought has a living presence and agent behind it. There are tantalising hints that even in respect of mathematics, Dummett's provisional realism has a theistic basis or that 'metaphysics' is for him far from being nonsense if a systematic theory of meaning underlies it. Indeed, says, Dummett, "If I have made any worthwhile contribution to philosophy, I think it must lie in having raised this issue in these terms." The implications are very wide and of the greatest importance.

It is the more regrettable that the two papers in which Dummett deals with the history of 'linguistic philosophies' in this country, and with the attacks (however technically inept) made on the narrowness, on the purely technical scholasticism of these philosophies, should decline to engage the real issue. This issue is not whether Strawson has been misinterpreted or whether Ayer has seen the importance of Frege's logic. It is whether or not the concerns which Professor Dummett so brilliantly pursues are central, are adequate to the concept of philosophy in society and the lives of individuals. The charge, and Dummett does not answer it, is simply this: Oxbridge linguistic logic has trivialised the enterprise of the philosopher. It has sought to eliminate ethics, aesthetics, metaphysics in the very sense in which Dummett invokes it. It has chosen to ignore, in Owen Chadwick's remarkable phrase, the extent to which, since the 1930s, "the agonies and passions of mankind started to enter and complicate the philosophies." The challenge is a real one. No-one would meet it better than Professor Dummett himself.

George Steiner is Professor of English and Comparative Literature at the University of Geneva, Switzerland.

\section{Panorama of modern neurobiology}

\section{Leslie Iversen}

Molecular Neurobiology of the Mammalian Brain. By P. L. McGeer, Sir John C. Eccles and E. G. McGeer. Pp. 644. (Plenum: New York and London, 1978.)

THIS substantial volume represents the results of an ambitious undertaking by two biochemists who have pioneered the application of biochemical approaches to studies of chemical neurotransmitters in the brain, and one of the most eminent neurophysiologists of our time. An ambitious undertaking because they seek to bring together in one volume virtually all of the achievements of modern cellular neurobiology and to show how far this basic information can be used to explain the integrative functions of the mammalian brain. This is promising stuff, and the reader is further encouraged by the authors' principle that they should provide not merely a bare factual account of present knowledge, but attempt to give some outline of the key events in the historical development of such knowledge from the interplay of hypothesis and experiment. We may even hope that the basic cellular data will throw some light on the workings of the human brain-"This organ, weighing about $1.5 \mathrm{~kg}$, is the most highly organised matter known in the universe".

The Molecular title indicates a leaning to the 'wet' approach to neuroscience, which emphasises the explanation of brain function in chemical terms; but this is in fact misleading, as virtually all aspects of cellular neuroscience are dealt with in the first and largest two sections of the book. These, in some 360 pages, review basic information on the architecture, organisation and signalling properties of neurones, and concepts of chemical synaptic transmission in the periphery

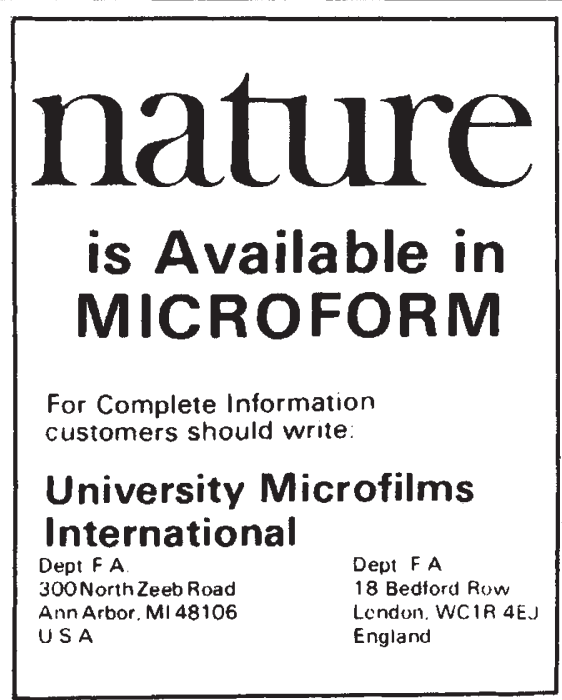

and in the central nervous system (CNS). A series of fairly detailed chapters summarise current knowledge of the specialised biochemical properties associated with neurones using acetylcholine, amino acids, catecholamines, or 5-hydroxytryptamine as transmitter, and others cover the new field of "promising peptides' and various other putative CNS transmitters, accompanied in each case by a brief outline of the actions of drugs on neurotransmitter mechanisms.

The coverage of neurotransmitters is good and up to date, although more explanation and examples could have been given of ligand-binding techniques for the study of neurotransmitter receptors in CNS, a development which has had a major impact on neurochemical studies of such mechanisms in recent years. The undue emphasis given to acetylcholine and catecholamines (almost 100 pages) continues to reflect the inadequacy of our current knowledge of other CNS transmitters, rather than the true importance of the monoamines in CNS function.

A third section of some 200 pages gives a wide-ranging review of integrative aspects of brain function, from development and plasticity to motor control mechanisms, learning and memory, and perception, speech and consciousness. The aim is to refer back in this section to the basic properties of neurones described previously. This aim is sometimes successfully achieved: for example, in the description of the extrapyramidal motor control systems in basal ganglia, in which anatomical, physiological and neurotransmitter aspects are well integrated, with discussion of human basal ganglia disease, such as Parkinsonism and Huntington's Chorea and their treatment by drugs, neatly interspersed. On the other hand, the description of cerebellar function completely omits any mention of the neurotransmitters involved, despite referance in earlier sections to the important role of the putative amino acid transmitters, $\gamma$-aminobutyric acid and glutamate, in this region of the brain. An ambitious chapter on basic aspects of behaviour includes a description of central endocrine influences and the CNS actions of psychoactive drugs, together with a review of current neuropharmacological theories of mental illness. As complexity increases with each succeeding chapter it is inevitable that the book ends with a discussion of perception and consciousness, in which the dualist-interactionist hypothesis-described in more detail in the recent book by K. R. Popper and J. C. Eccles The Self and Its Brain (Springer: Berlin, 1977; for review, see Nature, 272, 770, 1978)-is restated. The reader is given plenty of advance warning of this conclusion: in discussing the ques- 
tion of consciousness (p3) "We shall see that it is beyond our comprehension how these subtle properties of the conscious self came to be associated with a material structure, the human brain, that owes its origin to the biological process of evolution." However, whether one agrees or not with this strong dualist stance, we could all agree that "We believe it to be important for the molecular neurobiologist to be confronted with the problems arising in higher brain functions."

In any volume with as wide a scope as this one, each of us will no doubt find what seem to be important omissions or failures of emphasis. For example, I found it hard to understand why so little attention was given to a clear description of modern anatomical tracing techniques, using anterograde and retrograde flow of marker materials, in view of the enormous and continuing impact such techniques are having on our understanding of neuronal circuits in mammalian CNS. (Pick up any current issue of a brain research journal and count the number of papers involving peroxidase tracing methods!)

The overall impression left by this book is that of a courageous enterprise which did not quite succeed in its objectives. The variation in styles between the authors is often very obvious, and this together with the attempt to cover almost all aspects of mammalian neurobiology inevitably makes the book somewhat disjointed, with the individual chapters often divided and sub-divided over again into a multitude of smaller subsections. The illustrations, however, are copious and of excellent quality, and there is a substantial bibliography, with more than 1000 references (though with few more recent than 1976). One is left with admiration for the energies of the authors who have succeeded in putting together an attractive volume. but also in some doubt as to its likely readership. The book is probably too large and expensive to become widely used as a neurobiology student text, where other excellent volumes in any case already exist-for example, S. W. Kuffler and J. G. Nicholls' From Neuron to Brain (Sinauer Associates: Sunderland, Massachusetts; UK Publisher, Place, 1976). Nevertheless, it deserves to find a wide readership, and will certainly provide an accurate and sometimes inspiring panorama of modern neurobiology for those who want to know more about the field as a whole, or who feel the need to bring up to date what they thought they once knew.

Leslie Iversen is Director of the $M R C$ Neurochemical Pharmacology Unit Department of Pharmacology, University of Cambridge, UK.

\section{Boundaries of palaeo- anthropology}

\section{G. E. Kennedy}

Early Hominids of Africa. Edited by C. Jolly. Pp. 598. (Duckworth: London, 1978.) $£ 28$.

HistoriCally ill-defined, the boundaries of palaeoanthropology have recently been delineated by several excellent volumes. Although all of these volumes have emphasised the interdisciplinary character of palaeoanthropology, none has so effectively designated the scope and nature of the contributions from geology, anatomy, biology and archaeology better than this one.

Early Hominids of Africa is comprised of papers given at a conference held in New York more than five years ago. That the conference was organised (largely by Cliff Jolly, who also edited the volume) with care and some foresight is attested to by the overall currency and freshness of the papers. A number of the papers are, in fact, of considerable value in designating the current structure of the discipline.

Glynn Isaac, in his contribution, for example, discusses the scope of palaeolithic archaeology within the context of palaeoanthropological investigations. $\mathrm{He}$ points out that such studies focus less on traditional questions of tool typology and more on broader areas of tool function and the behaviour, selection and origin of raw materials. His suggestion that tools represent "self-recording behaviours" typifies the approach where more detailed and subtle questions are now asked of empirical data than was usual in earlier years.

So, too, with the palaeoecological papers contributed by Butzer, Behrensmeyer and Cooke. These papers, each from a different research perspective, focus on the reconstruction of the environmental context of the early hominids. Butzer's paper is perhaps the most successful of these and indicates the new directions taken by the various contributory disciplines within the context of palaeoecological reconstructions. Butzer argues that many of the environmentally deterministic models of anthropoid and hominid evolution were erroneously based on unidimensional reconstructions and both the environment and the sources of selective pressures were more complex than the earlier, more simplistic models would allow.

The section on anatomical evidence, the largest in the book, reflects a strong trend in research interests away from the cranium; all but two of the papers deal with analyses of postcranial anatomy and locomotor capabilities. Papers by Day, Robinson and Lovejoy are informative in these areas, although they provide little that has not been published elsewhere. The two papers on cranial morphology are innovative and highly specialised. Wallace's study on the ramifications of early closure of the premaxillary suture in hominids is both insightful and soundly based on the fossil evidence. His discussion on the ontogenetic, phylogenetic and adaptive aspects of this process is an excellent example of the subtlety of the questions now being asked of the fossil data. So, too, with Holdoway's discussion of endocranial casts which continues his series of stimulating, frank and challenging papers.

A section devoted to the interpreta. tion of diversity in early hominid samples continues the interdisciplinary theme. Delson's paper on cladistic analysis, which emphasises trait congruity as a taxonomic tool, contrasts strongly with Campbell's, which seems to emphasise temporal congruity for the same purposes. Simons contributed an analysis of hominid evolution from a vertebrate palaeontologist's viewpoint. Although valuable for methodological as well as interpretative reasons, this paper is of particular interest for its discussion of Ramapithecus freybergi, a later Miocene hominid from a site near Athens.

Papers on the most productive of the east and south African localities were submitted by the sites' principal investigators. Although much of this information has been published elsewhere, these concise summaries are useful.

The long delay in publication has resulted in very few shifts in the interpretation of data. The most noticeable of these shifts involves Johanson's evaluation of hominid material recovered at Hadar, Ethiopia. In 1972, he suggested that two taxa were present at Hadar, a view recently formally rejected in favour of a single taxon. The only significant criticism which can be levelled at this volume is the cost. The high price will put it beyond the reach of most advanced undergraduate and gradute students, groups which would benefit most from it.

G. E. Kennedy is Assistant Professor of Anthropology at the University of California, Los Angeles, California. 